\title{
Challenges to improve the biopharmaceutical properties of poorly water-soluble drugs and the application of the solid dispersion technology
}

\author{
Gabriela Tambosi ${ }^{1}$, Paola Felippi Coelho ${ }^{2}$, Luciano Soares ${ }^{1,3}$, \\ Iára Cristina Schmücker Lenschow ${ }^{1}$, Melissa Zétola ${ }^{3}$, \\ Hellen Karine Stulzer ${ }^{2}$, Bianca Ramos Pezzini ${ }^{1,2}$
}

\author{
${ }^{1}$ Programa de Pós-Graduação em Saúde e Meio Ambiente, Universidade da Região de Joinville, 89219-710, Joinville, \\ Santa Catarina, Brasil. \\ ${ }^{2}$ Programa de Pós-Graduação em Farmácia, Universidade Federal de Santa Catarina, 88040-900, Florianópolis, Santa \\ Catarina, Brasil. \\ ${ }^{3}$ Departamento de Farmácia, Universidade da Região de Joinville, 89219-710, Joinville, Santa Catarina, Brasil. \\ e-mail: gabitambosi@yahoo.com.br,pfcoelho@outlook.com, soaresgnosia@gmail.com, iara.ics@gmail.com, \\ mel.zetola@gmail.com, hellen.stulzer@ufsc.br, bianca.pezzini@ufsc.br
}

\begin{abstract}
The oral solid dosage forms are extremely relevant to drug therapy and responsible for much of the pharmaceutical industry turnover worldwide. However, the development of medicines in solid form involves significant challenges, including obtaining formulations with appropriate bioavailability for low aqueous solubility drugs (classes II and IV of the Biopharmaceutics Classification System). One of the most effective strategies to overcome poor dissolution rate and low absorption of drugs is the solid dispersion technique, however, although it has been the focus of much research in recent decades, there are relatively few commercially available products based on such technology. This is mainly due to problems related to production scale-up and physicochemical instability and creates opportunities for new studies to explore the full potential of the technology. This review presents an overall approach to the factors affecting the dissolution rate and oral bioavailability of BCS-classes II and IV drugs and a brief review of the state-of-the-art of solid dispersion technology.
\end{abstract}

Keywords: oral delivery, drug solubility, drug dissolution, solid dispersion.

\section{INTRODUCTION}

The oral route is the most commonly used for drug administration due to significant inherent advantages compared to other routes, such as safety, non-invasive nature, convenience and comfort to the patient, possibility of self-administration and systemic distribution of the drug. Among all types of oral dosage forms, the solid ones, such as tablets and capsules, are the most used in therapy, because they offer many benefits, such as simplicity and low cost of production, high stability, convenience of the presentation in unit doses, portability, ease of administration and masking the unpleasant taste of many drugs [1,2].

A major obstacle to the development and large-scale production of oral solid dosage forms is the low solubility of many drugs, given the negative effect that this property has on drug absorption and bioavailability. Concern about drug solubility in the pharmaceutical industry has intensified from the 90s, when the use of techniques, such as combinatorial chemistry and high throughput screening (HTS), increased the achievement of new chemical entities with high molecular weight and high lipophilicity [3,4]. Recognizing that drug dissolution and gastrointestinal permeability are the fundamental parameters controlling the rate and the extent of drug absorption grounded the proposition of the Biopharmaceutical Classification System (BCS) for correlating drug product in vitro dissolution and in vivo bioavailability, in which classes II and IV encompass drugs with low solubility $[5,6,7]$.

The need for effective formulations for BCS-classes II and IV drugs led to the progress of knowledge in the area of drug delivery systems for oral administration, over the years, and to the development of various technological strategies to remedy unsatisfactory biopharmaceutical properties, for example, micronization [8], formation of complexes with cyclodextrins [9], self-emulsifying drug delivery systems (SEDDS) [10], 
liquisolid systems [11, 12] and solid dispersions [13, 14].

Large investments in research and development of solid dispersions brought good results for the pharmaceutical industry, with the emergence of products based on this technology on the market. Nevertheless, there is still plenty of room for improvement, aiming to overcome some limitations of the solid dispersion technology. Additional studies for development and improvement are still needed regarding the production processes, carrier materials and stabilization strategies, so that the full potential of solid dispersions is explored, thus resulting in increased number of commercially available products $[13,15]$. This review presents an overall approach to the factors affecting the dissolution and oral bioavailability of BCS-classes II and IV drugs and a brief review of the state-of-the-art of solid dispersion technology.

\section{ORAL ADMINISTRATION OF POORLY WATER-SOLUBLE DRUGS}

For producing the desired pharmacological response after oral administration, as shown in Figure 1, a dosage form must release the drug in the gastrointestinal tract to be absorbed, reach the systemic circulation, and be distributed in the site of action in the body at sufficient rate and extent $[16,17]$. The term bioavailability refers to the rate and extent at which the active drug reaches the systemic circulation $[17,18,19]$. Many factors may influence the bioavailability of drugs, which may be related to the dosage form, the manufacturing process and the drug itself [20, 21, 22, 23].

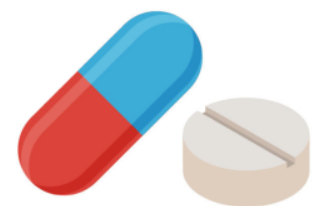

DOSAGE FORM
PHARMACOLOGICAL EFFECT

Oral administration
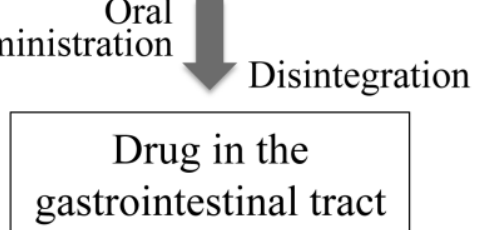

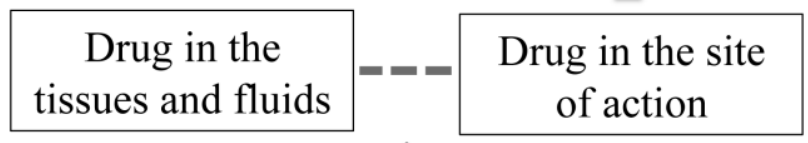

Distribution

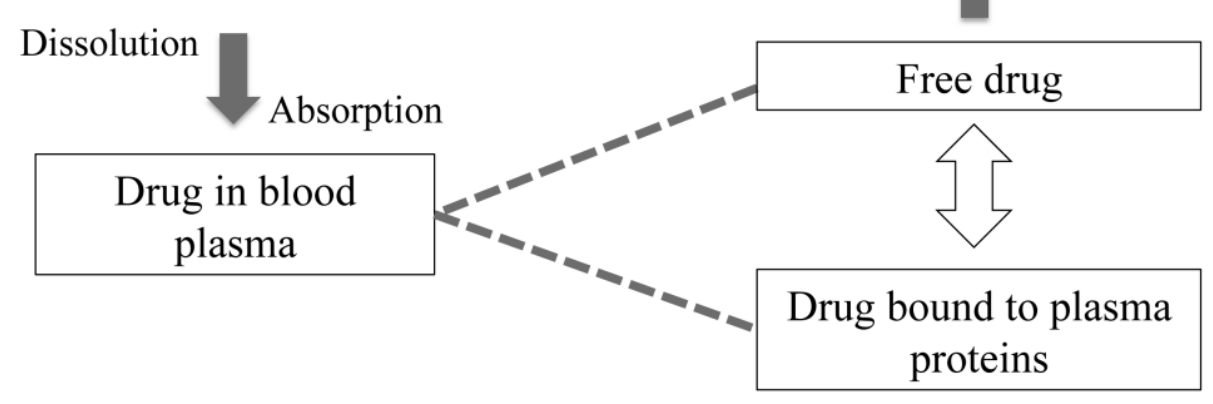

Figure 1: Steps involved in the release from a solid dosage form and gastrointestinal absorption of a drug [17].

\subsection{Factors affecting drug bioavailability: related to the pharmaceutical dosage form and to the manu- facturing process}

The dosage form needs to undergo several steps after oral administration to occur the release of the drug, and for making it bioavailable. Factors and characteristics related to the dosage form itself may interfere with drug release, for example, the manufacturing process, the nature of the excipients, the disintegration time and the drug release rate $[20,21,22,23]$.

The manufacturing processes can subject the components of the formulation to mechanical or thermal stress, which can induce phase transitions of certain drugs (interconversion of polymorphs, solvates/hydrates or amorphous form), thereby altering their chemical, physical, mechanical and biopharmaceutical (drug dissolution and bioavailability) properties. Examples of manufacturing operations that can trigger polymorphic transformations are granulation, spray drying, grinding, mixing, compression, encapsulation, and coating [21, 22, 23].

The selected excipients and processing operations can influence the disintegration properties of the 
dosage form and therefore the drug dissolution profile and bioavailability. The greater the rate of disintegration of the dosage form, the more rapidly the drug can progress to the steps of dissolution and absorption. Excipients possessing favorable characteristics of compactness, for example, allow the replacement of the wet granulation process by direct compression, the last usually resulting in tablets with faster disintegration. Also, using water-soluble and swellable excipients favors the disintegration of the dosage form and drug release, and, on the contrary, the use of insoluble excipients may hinder the disintegration and dissolution steps $[20,21,22,23]$.

\subsection{Factors affecting drug bioavailability: related to the drug}

Factors inherent to the drug itself that influence its absorption and bioavailability include physicochemical properties (e.g. solubility, stability, polymorphism); solid state (amorphous, crystalline); particle size; transport across intestinal membrane; and metabolism [21, 22, 24].

The drug must be dissolved in the gastrointestinal environment to be then absorbed. The solubility of the drug is the main limiting factor for its dissolution, as the aqueous nature of the gastrointestinal contents causes poorly-water soluble drugs to present low saturation solubility and thus a lower dissolution rate $[6,19]$. The main drug absorption mechanism in the gastrointestinal tract (GIT) occurs by passive diffusion; therefore, the absorption is favored when the drug is presented in the non-ionized state, in its more lipophilic form, which enables the permeation through cell membranes [25].

Particle size may influence drug bioavailability, i.e., the smaller the particle size, the larger the surface area of the substance in contact with the dissolution medium, and thus the higher the dissolution rate and the absorption of the drug $[8,26]$.

The amorphous form of a drug can lead to improved bioavailability compared to the crystalline form. Crystalline solids are those in which atoms, ions or molecules have a periodic arrangement, that is, that repeats regularly in the three dimensions. Amorphous solids don't have long-range spatial ordering, tend to be more energetic than crystalline ones, and therefore usually have distinct physicochemical properties, such as higher solubility and higher dissolution rate. Although they exhibit inferior solubility and dissolution properties, crystalline drugs are more frequently used in pharmaceutical formulations because amorphous ones generally exhibit lower physical and chemical stability, with a tendency to crystallization and degradation [24].

Polymorphism affects the solubility, the stability, the dissolution rate and the bioavailability of drugs. Polymorphs are crystalline phases containing the same molecules but having different conformations and/or packing arrangements in the solid-state. Although these molecules are chemically identical, the polymorphs have different physicochemical properties such as melting point, solubility and hygroscopicity. Anhydrous forms of drugs, for example, have a higher thermodynamic activity compared to the corresponding hydrates, and, consequently, increased solubility and dissolution rate. Different polymorphic forms can arise from the conditions employed in the synthesis and purification of the drug, depending, for example, on the type of solvent used and the reaction temperature [24, 27, 28].

Once absorbed, the drug passes through the liver and may undergo metabolization or biliary excretion before reaching the systemic circulation and being delivered to the site of action. When this capacity of the liver to metabolize and excrete the drug is high, the bioavailability is significantly reduced; this phenomenon is called first-pass metabolism. Therefore, the amount of drug that reaches the systemic circulation depends not only on the administered dose but also to the fraction of this dose that is absorbed and passes unchanged through the liver, without suffering any first-pass effect. This fraction is the amount of drug that is bioavailable to perform its therapeutic function [25].

After metabolization, the unchanged fraction of the drug is distributed by the blood to the tissues where it will exert the pharmacological effect. Many substances circulate in the bloodstream bound to plasma proteins, mainly albumin. This binding to plasma proteins limits the distribution of the drug, as only the free fraction is able to cross membranes and reach the site of action [25].

\subsection{Low solubility drugs (BCS classes II and IV)}

In recent years, there has been an increase in developing drugs with high molecular weight and lipophilicity. As a result, approximately $40 \%$ of drugs with market approval and about $90 \%$ of molecules in the discovery pipeline show low water solubility [29].

Low dissolution rate arising from poor solubility frequently leads to low bioavailability of orally administered drugs, thus resulting in limited therapeutic potential and unsatisfactory clinical outcomes $[6,30]$. In some cases, dose escalation becomes necessary to allow therapeutic concentrations of the drug to be 
reached in the blood, which can lead to topical toxicity in the GIT and negatively affect patient adherence to treatment [6].

A useful decision-making tool in the development of oral pharmaceutical formulations is the Biopharmaceutics Classification System (BCS), proposed by Amidon et al., in 1995, which categorize the drugs based on their water solubility and intestinal permeability [5, 7, 31].

BCS categorizes drugs into four classes, namely: class I (high solubility and high permeability), class II (low solubility and high permeability), class III (high solubility, low permeability) and class IV (low solubility and low permeability) [5,7]. For classification purposes, American regulatory body Food and Drug Administration (FDA) considers a highly soluble drug when the highest dose strength is soluble in $<250 \mathrm{ml}$ of water over a $\mathrm{pH}$ range of 1 to 7.5. A drug substance is considered highly permeable by FDA when the extent of absorption in humans is determined to be $>90 \%$ of an administered dose, based on mass-balance or in comparison to an intravenous reference dose [31].

Drugs with a low water solubility (BCS-classes II and IV) have great potential for low bioavailability when administered in oral solid dosage forms. Dissolution is the limiting step for BCS-class II drugs absorption, which is impaired due to the low water solubility of the compound. While these drugs are highly permeable, the low solubility produces a low concentration gradient between the intestine and the bloodstream, limiting transport across the biological membranes and absorption. Besides low solubility, BCS-class IV drugs have low permeability as an additional factor that hinders the absorption $[5,7,31]$.

\section{SOLID DISPERSIONS}

A solid dispersion is a dispersion, in the solid state, of a drug (or more than one) in a matrix formed by a hydrophilic carrier (or by an association of carriers). Solid dispersion technology has been successfully applied in the development of formulations aimed at the improvement of the dissolution profile and bioavailability of poorly water-soluble drugs $[13,32,33,34,35,36,37]$. Mechanisms that can be involved are the reduction of drug particle size, possibly down to the molecular level; the increased wettability of the drug; formation of soluble drug-carrier complexes; and amorphization of the drug [13,34]. It is important to mention that solid dispersions are intermediate products that have to be incorporated in a final dosage form, such as capsules or tablets [13]. Some examples of commercially available pharmaceutical products based on solid dispersion technology are listed in Table 1.

Table 1: Examples of commercially available pharmaceutical products based on solid dispersions.

\begin{tabular}{l|l|l|l|l}
\hline TRADE NAME & MANUFACTURER & DRUG & CARRIER & DOSAGE FORM \\
\hline Afeditab CR & Actavis & Nifedipine & Poloxamer/PVP & Tablet \\
\hline Certican & Novartis & Everolimus & HPMC & Tablet \\
\hline Crestor & AstraZeneca & Rosuvastatin & HPMC & Tablet \\
\hline Fenoglide & Salix & Fenofibrate & PEG & Tablet \\
\hline Gris-PEG & Pedinol & Griseofulvin & PEG & Tablet \\
\hline Incivek & Vertex & Telaprevir & HPMCAS & Tablet \\
\hline Incivo & Janssen & Telaprevir & HPMCAS & Tablet \\
\hline Intelence & Janssen & Etravirine & HPMC & Tablet \\
\hline Isoptin SR-E & Abbott & Verapamil & HPC/HPMC & Tablet \\
\hline Kaletra & Abbott & Lopinavir, ritonavir & PVPVA & Tablet \\
\hline Kalydeco & Vertex & Ivacaftor & HPMCAS & Tablet \\
\hline Nimotop & Bayer & Nimodipine & PEG & Tablet \\
\hline Nivadil & Fugisawa & Nilvadipine & HPMC & Tablet \\
\hline Noxafil & Merck & Posaconazole & HPMCAS & Tablet \\
\hline Norvir & Abbott & Ritonavir & PVPVA & Tablet \\
\hline Onmel & Stiefel & Itraconazole & HPMC & Tablet \\
\hline Prograf & Fugisawa & Tacrolimus & HPMC & Capsule \\
\hline Sporanox & Janssen & Itraconazole & HPMC & Capsule \\
\hline Zelboraf & Roche & Vemurafenib & HPMCAS & Tablet \\
\hline Zortress & Novartis & Everolimus & HPMC & Tablet \\
\hline
\end{tabular}

HPMC: hydroxypropyl methylcellulose; HPMCAS: hydroxypropyl methylcellulose acetate succinate; HPC: hydroxypropyl cellulose; PEG: polyethylene glycol; PVP: polyvinylpyrrolidone; PVPVA: polyvinylpyrrolidone-covinyl acetate.

$[13,33,35,36,37]$. 
Although the number of components is not limited to two, solid dispersions usually are binary systems in which the drug and the carrier can exist in different arrangements (Figure 2): (A) the drug is molecularly dispersed in the matrix formed by the carrier; (B) crystalline drug particles are dispersed in the carrier matrix; (C) amorphous drug particles are dispersed in the carrier matrix [33].

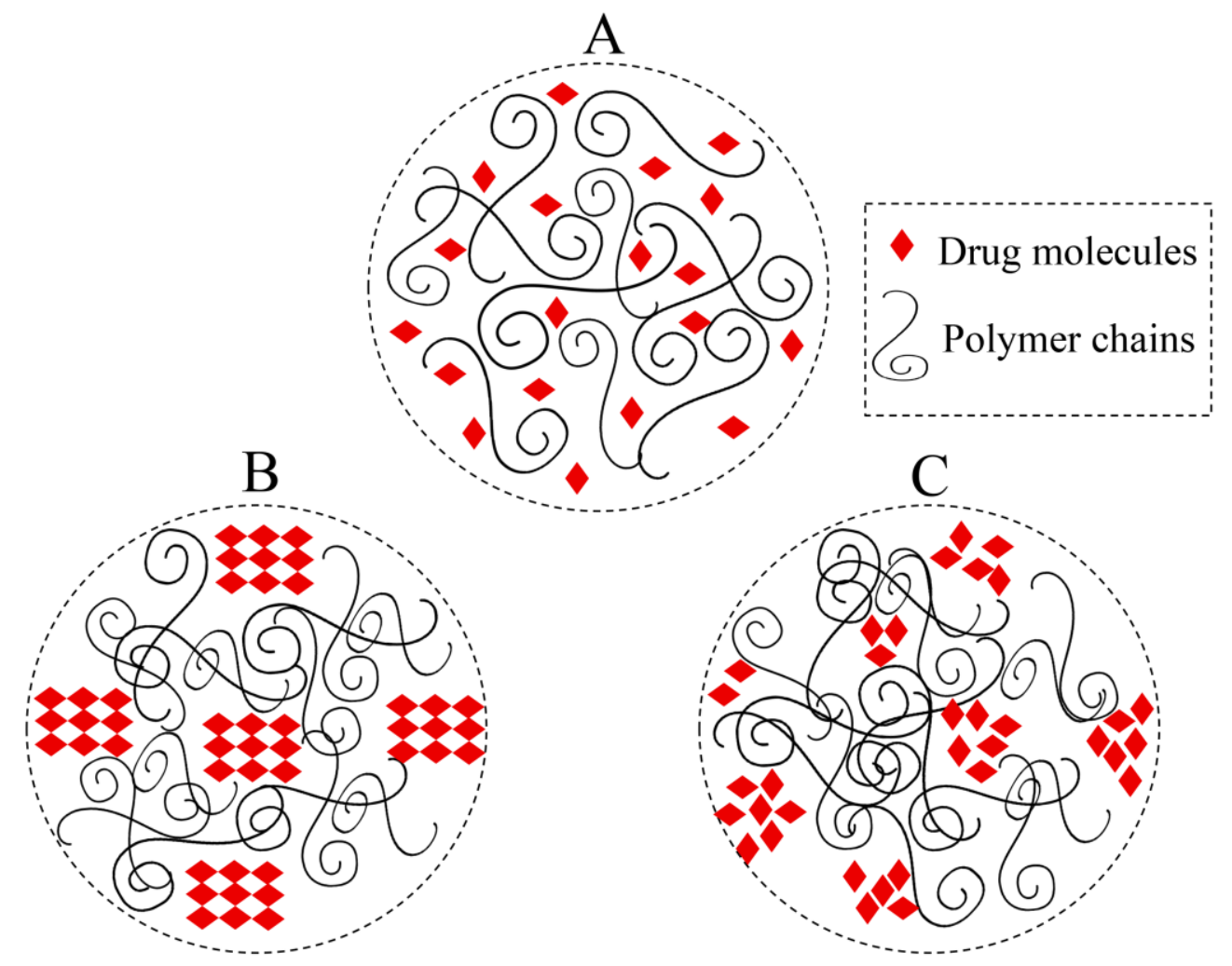

Figure 2: Possible arrangements between drug and carrier in polymeric solid dispersions: (A) the drug is molecularly dispersed in the matrix formed by the polymeric carrier; (B) the drug in the crystalline state is dispersed in the polymeric matrix; (C) domains rich in amorphous drug are dispersed in the polymeric matrix [33].

Solid dispersions are classified in eutectic mixtures, solid solutions, glass solutions, or glass suspensions [35] whose definitions and mechanisms for drug dissolution improvement are presented in Table 2. Solid dispersions are also classified into four generations based on the advancement of knowledge and complexity of the system [13] as compared in Table 3 and described in 3.1. 
Table 2: Categories of solid dispersions: state of the drug, number of phases, definitions, and mechanism involved in drug dissolution enhancement.

\begin{tabular}{|c|c|c|c|c|}
\hline $\begin{array}{l}\text { CATEGORY } \\
\text { OF SOLID } \\
\text { DISPERSION } \\
\end{array}$ & $\begin{array}{l}\text { STATE OF } \\
\text { THE DRUG }\end{array}$ & $\begin{array}{l}\text { NUMBER OF } \\
\text { PHASES }\end{array}$ & DEFINITION & $\begin{array}{l}\text { MECHANISM FOR DRUG } \\
\text { DISSOLUTION ENHANCE- } \\
\text { MENT }\end{array}$ \\
\hline Solid solution & Crystalline & 01 & $\begin{array}{l}\text { Solution formed by the incorpo- } \\
\text { ration of the drug molecules } \\
\text { into the crystal lattice of the } \\
\text { carrier. }\end{array}$ & $\begin{array}{l}\text { The particle size of the drug is } \\
\text { reduced to its molecular di- } \\
\text { mensions. }\end{array}$ \\
\hline $\begin{array}{l}\text { Eutectic mix- } \\
\text { ture }\end{array}$ & Crystalline & 02 & $\begin{array}{l}\text { Mixture of two compounds that } \\
\text { are completely miscible in the } \\
\text { liquid state (melt) but show } \\
\text { limited miscibility in the solid- } \\
\text { state form. At a specific compo- } \\
\text { sition, the two components } \\
\text { crystallize simultaneously when } \\
\text { the temperature is reduced. }\end{array}$ & $\begin{array}{l}\text { Once in contact with aqueous } \\
\text { GIT fluids, the carrier dis- } \\
\text { solves rapidly and release fine } \\
\text { crystals of the drug. Drug } \\
\text { dissolution rate is enhanced } \\
\text { due the large surface area and } \\
\text { the improved wettability from } \\
\text { the carrier. }\end{array}$ \\
\hline Glass solution & Amorphous & 01 & $\begin{array}{l}\text { Solution where the drug is dis- } \\
\text { persed molecularly in the amor- } \\
\text { phous carrier. }\end{array}$ & $\begin{array}{l}\text { The particle size of the drug is } \\
\text { reduced to its molecular di- } \\
\text { mensions. }\end{array}$ \\
\hline $\begin{array}{l}\text { Glass suspen- } \\
\text { sion }\end{array}$ & Amorphous & 02 & $\begin{array}{l}\text { Suspension containing the drug } \\
\text { in a separate amorphous phase } \\
\text { dispersed in the amorphous } \\
\text { carrier. }\end{array}$ & $\begin{array}{l}\text { The drug dissolution rate is } \\
\text { still increased compared to } \\
\text { the crystalline form of the } \\
\text { drug since the drug is still in } \\
\text { the amorphous state in the } \\
\text { glass suspension. }\end{array}$ \\
\hline
\end{tabular}

Table 3: Characteristics of the four generations of solid dispersions.

\begin{tabular}{|c|c|c|c|c|}
\hline & \multicolumn{4}{|c|}{ SOLID DISPERSION GENERATION } \\
\hline & First & Second & Third & Fourth \\
\hline Type of carrier & Crystalline material & Amorphous polymer & $\begin{array}{l}\text { Surfactant or surfac- } \\
\text { tant-amorphous poly- } \\
\text { mer mixture }\end{array}$ & $\begin{array}{l}\text { Water insoluble poly- } \\
\text { mer or swellable pol- } \\
\text { ymer }\end{array}$ \\
\hline Main properties & $\begin{array}{l}\text { - Lower dissolution } \\
\text { rates compared to } 2 \text { nd } \\
\text { generation due to } \\
\text { crystalline carrier } \\
\text { - Low stability }\end{array}$ & $\begin{array}{l}\text { - Higher drug dissolu- } \\
\text { tion rates compared to } \\
\text { 1st generation } \\
\text { - Precipitation under } \\
\text { supersaturation } \\
\text { - Low stability }\end{array}$ & $\begin{array}{l}\text { - Highest dissolution } \\
\text { rate } \\
\text { - Decreased precipita- } \\
\text { tion under supersatura- } \\
\text { tion } \\
\text { - Increased stability }\end{array}$ & $\begin{array}{l}\text { - Increased dissolution } \\
\text { rate } \\
\text { - Sustained-release }\end{array}$ \\
\hline
\end{tabular}

[13].

\subsection{Generations of solid dispersions}

\subsubsection{First-generation solid dispersions}

The first description of a solid dispersion was a eutectic mixture of sulfathiazole and urea by Sekiguchi and Obi in 1961 [34, 38, 39]. In this same decade, the use of the technique has been described for other drugs giving rise to the so-called first-generation solid dispersions, or crystalline solid dispersions, characterized by the use of crystalline carriers [13,34]. Crystalline carriers can form solid dispersions that are eutectic mixtures (the melting point of the mixture is lower than the melting point of the drug and carrier), monotectic mixtures (the melting point of the carrier and drug are constant) or interstitial solid solutions (drug molecules occupy the interstitial spaces between the solvent molecules in the crystal lattice) [13, 40]. Eutectics are more preferable (as compared to monotectics) because both the drug and carrier crystallize simultaneously in the cooling process, resulting in a well-dispersed state of the drug in carrier [13].

Examples of crystalline carriers used in solid dispersions are urea, organic acids (e.g. citric acid and succinic acid), and sugars (e.g. mannitol, xylitol, sucrose, dextrose, and galactose) [40].

The main disadvantage of the first generation solid dispersions is the high thermodynamic stability of 
the carrier, which promotes lower dissolution rates compared with amorphous solid dispersions [13, 34]. Also, the high melting point of some carriers used in crystalline solid dispersions complicates the preparation of such systems by the melting method [13,14]. Urea, organic acids, and most sugars (mannitol is an exception) are thermally unstable; therefore, they are unsuitable for solid dispersion preparation by the melting method. In addition, obtaining solid dispersions by solvent-based process using sugars as carriers is infeasible because they are poorly soluble in nonaqueous solvents and also are unable to retard drug crystallization during solvent evaporation [40].

\subsubsection{Second-generation solid dispersions}

A second generation of solid dispersions was developed using amorphous carriers, which are mostly polymers [13, 33, 34]. Such solid dispersions, called amorphous solid dispersions, may be classified as glass solid solutions, glass suspensions or a mixture of both, according to the physical state of the drug [13, 34]. As stated in Table 2, in glass solutions, the drug and the carrier are completely miscible, so that they form a homogeneous molecular mixture, while glass suspensions consist of two separate phases [13, 35]. Glass suspensions are formed when the drug has a limited solubility in the carrier or an extremely high melting point [13, 35].

Some examples of polymers used in second generation solid dispersions are polyvinylpyrrolidone (PVP), crospovidone, polyvinypyrrolidone-co-vinylacetate (PVPVA), polymethacrylates, cellulose derivatives [e.g. hydroxypropylcellulose (HPC), hydroxypropylmethyl cellulose (HPMC), hydroxylpropylmethylcellulose acetate succinate (HPMCAS), hydroxypropylmethylcellulose phthalate (HPMCP), ethylcellulose (EC)], starch and cyclodextrins] [13, 34, 41].

\subsubsection{Third-generation solid dispersions}

Amorphous drugs can recrystallize from solid dispersions during obtaining process (cooling or removal of solvent) or storage, and also can precipitate after the achievement of a supersaturation state in vivo, adversely affecting drug bioavailability. Therefore, the main objective in formulating third-generation solid dispersions is to overcome problems related to drug recrystallization and precipitation [13, 34].

Third-generation solid dispersions contain surfactants, self-emulsifiers, or mixtures of amorphous polymers and surfactants as carriers. The addition of surfactants in the solid dispersion can improve drug dissolution by increasing drug wettability and solubility. Surfactants also improve the physical stability of solid dispersions because they aid in drug-polymer miscibility and reduce drug recrystallization. Furthermore, the use of surfactants in solid dispersions can prevent drug precipitation in the aqueous medium. However, caution must be employed in selecting the surfactant because in some cases it can interact with polymer and thereby increase drug recrystallization [13, 34, 42].

Examples of surfactants used in third-generation solid dispersions are poloxamer 407, poloxamer 188, Compritol $^{\circledR} 888$ ATO, Gelucire ${ }^{\circledR} 44 / 14$, Inutec ${ }^{\circledR}$ SP1 [13,34], Soluplus ${ }^{\circledR}$, sodium lauryl sulfate (SLS), polysorbate 80 , polyoxyethylene hydrogenated castor oil [34, 42].

\subsubsection{Fourth generation solid dispersions}

The fourth-generation of solid dispersions encompasses sustained-release (or controlled-release) systems containing drugs with low water solubility and short plasma half-life. The drug dispersed molecularly in the carrier becomes more soluble in aqueous media whereas insoluble or swellable polymers are used to sustain the drug release in the dissolution medium [13]. The hydrophilic and swellable properties of swellable polymers make them ideal carriers for sustained-release solid dispersions because they have two advantageous functions in nature: improving drug solubility and sustaining drug release (by swelling, diffusion and erosion mechanisms) [43].

The benefits of fourth-generation solid dispersions include those typical of sustained-release drug delivery systems, i.e., reduced dosing frequency, reduction of side effects, and improved adherence to the treatment by the patient [13].

Some carriers used in fourth-generation solid dispersions are ethyl cellulose (EC), HPC, Eudragit ${ }^{\circledR}$ RS, Eudragit $^{\circledR}$ RL, poly(ethylene oxide) [PEO], carboxyvinyl polymer $\left(\right.$ Carbopol $\left.^{\circledR}\right)$ [13], sodium carboxymethylcellulose (Na-CMC), and HPMC [43].

\subsection{Stabilization of solid dispersions}

Drugs in the amorphous state have higher molecular mobility and increased thermodynamic properties, 
which confers to them higher apparent water solubility, dissolution rate, and oral absorption when compared to crystalline forms. However, these thermodynamic characteristics are the same that provides lower chemical and physical stability. Therefore, pure amorphous drugs are rarely used in pharmaceutical formulations due to their inherent higher reactivity and tendency to convert to a stable crystalline form. On the other hand, the solubility advantage of the amorphous form can be retained if the amorphous drug is stabilized into a matrix of excipient(s) in the form of a solid dispersion [36, 44].

Amorphous solid dispersion, wherein a crystallizable, small molecule drug disperses in an amorphous polymer matrix, is one of the most promising and viable formulation strategies for poorly water-soluble drugs [45]. For the success of such strategy the drug in the solid dispersion needs to remain in the amorphous state during manufacture operations; storage; and also after the intake by the patient, without recrystallization of the supersaturated solution formed in the gastrointestinal fluids [36, 44].

Drug recrystallization can be avoided in amorphous solid dispersion by minimizing molecular mobility and forming an energetic barrier to thermodynamic reactions. The stabilization mechanisms can involve: a physical barrier to crystallization; reduction in the chemical potential of the drug; anti-plasticization; and drug-polymeric interactions $[36,44,45]$ as explained in Table 4.

Table 4: Mechanisms involved in the stabilization of amorphous solid dispersions.

\begin{tabular}{|c|c|}
\hline MECHANISM OF STABILIZATION & EXPLANATION \\
\hline Physical barrier to crystallization & $\begin{array}{l}\text { Phase separation and crystallization of amorphous materi- } \\
\text { als demand diffusion and nucleation, both phenomena } \\
\text { involving molecular mobility. The incorporation of drug } \\
\text { molecules (amorphous drug) into the network formed by } \\
\text { the polymeric carrier in an amorphous solid dispersion } \\
\text { hinders the molecular mobility of the drug and reduces its } \\
\text { tendency to crystallization. }\end{array}$ \\
\hline Reduction in the chemical potential of the drug & $\begin{array}{l}\text { Amorphous drugs have high chemical potential, which acts } \\
\text { as a driving force for crystallization. Mixing the amor- } \\
\text { phous drug with a polymer, forming a miscible amorphous } \\
\text { system, lowers the chemical potential of the drug and its } \\
\text { tendency to crystallize. }\end{array}$ \\
\hline Anti-plasticization & $\begin{array}{l}\text { Using a polymer with high } \mathrm{Tg} \text { (glass transition tempera- } \\
\text { ture) as carrier increases the } \mathrm{Tg} \text { of the amorphous solid } \\
\text { dispersion as compared to the } \mathrm{Tg} \text { of the drug, which in- } \\
\text { creases the free energy required by the amorphous drug to } \\
\text { convert into the crystalline form. }\end{array}$ \\
\hline Drug-polymer intermolecular interactions & $\begin{array}{l}\text { Formation of intermolecular interactions (ion-dipole inter- } \\
\text { actions and intermolecular H-bonding) between the drug } \\
\text { and the polymeric carrier blocks drug-drug interactions } \\
\text { that can form the crystal lattice. }\end{array}$ \\
\hline
\end{tabular}

$[36,44,45]$.

\subsection{Preparation methods}

The classic methods described in the literature for preparing solid dispersions are the fusion method, the solvent method and the fusion solvent method. The two first are the most common and manufacturing processes fusion-based and solvent-based are available for industrial applications [13]. Mechanical processes such as ball milling or grinding can also be used but the degree of amorphization is usually lower in comparison with fusion and solvent methods $[13,14,35,36,46]$. The main obtaining methods for solid dispersions are briefly described below and their advantages and limitations are presented in Table 5. 
Table 5: Advantages and limitations of methods used for preparing solid dispersions.

\begin{tabular}{|c|c|c|}
\hline PREPARATION METHOD & ADVANTAGES & $\begin{array}{l}\text { LIMITATIONS } \\
\end{array}$ \\
\hline Fusion-based & - Solvent free & $\begin{array}{l}\text { - Use of high temperature } \\
\text { - Drug and carrier have to be miscible } \\
\text { at the heating temperature } \\
\text { - Drug and carrier have to be thermal- } \\
\text { ly stable at the heating temperature }\end{array}$ \\
\hline Solvent-based & $\begin{array}{l}\text { - Applicability for thermo labile drugs } \\
\text { and carriers because it does not re- } \\
\text { quire high temperature } \\
\text { - Enables the use of high-melting } \\
\text { point carriers, which can not be used } \\
\text { in fusion method }\end{array}$ & $\begin{array}{l}\text { - Difficulty of selection of a solvent } \\
\text { capable of solubilizing both the hy- } \\
\text { drophobic drug and the hydrophilic } \\
\text { carrier } \\
\text { - Generation of toxic residues } \\
\text { - The need to evaporate a large } \\
\text { amount of the solvent makes the pro- } \\
\text { cess expensive }\end{array}$ \\
\hline Fusion-solvent method & $\begin{array}{l}\text { - Temperature and mixing time are } \\
\text { lower than in fusion method, thus } \\
\text { protecting the drug from thermal deg- } \\
\text { radation } \\
\text { - The carrier in the molten state is } \\
\text { more easily dispersed and dissolved in } \\
\text { the solvent in comparison with solvent } \\
\text { method }\end{array}$ & $\begin{array}{l}\text { - Limited application with few reports } \\
\text { in literature compared to other meth- } \\
\text { ods }\end{array}$ \\
\hline Co-grinding & $\begin{array}{l}\text { - Solvent free } \\
\text { - Environmentally friendly } \\
\text { - Low cost, simple equipment, easy to } \\
\text { scale up }\end{array}$ & $\begin{array}{l}\text { - Grinding can result in a mixture of } \\
\text { amorphous and nanocrystalline drug, } \\
\text { and the last can act as seeds to induce } \\
\text { drug nucleation and recrystallization }\end{array}$ \\
\hline
\end{tabular}

$[13,14,34,35,36,47,48,49]$

\subsubsection{Fusion method}

In the fusion method (or melting method), drug and carrier are heated together to the lowest temperature above the melting points of them both, or the drug is incorporated into the melted carrier, the mixture remains under heating until a homogeneous solution is obtained then it is cooled rapidly. For cooling and solidification of the molten mixture, various techniques may be used, such as agitating in an ice bath; placing in a freezer; spreading a thin layer on stainless steel and cooling by air or water; immersion in liquid nitrogen; among others. The final mass is crushed, pulverized and sieved [13, 14, 35, 36, 46].

Fusion-based processes available at industrial scale involve melt agglomeration or melt extrusion [13, 35, 46]. Melt agglomeration processes use standard granulation equipment (e.g. high shear mixer or fluid bed dryer), where a melted mass of drug and carrier(s) is added to the powdered excipients of the formulation as a granulation liquid. The molten material ensures the adsorption of the drug and carrier(s) on the powdered excipients and the resultant granules are then processed to obtain the final dosage form [46].

In hot melt extrusion, the material (drug and polymer) melts under high temperature and is further forced through a die with the help of one or two conveyor screws in a barrel, resulting in a product of uniform shape. Individual components within the extruder are the feed hopper, a temperature controlled barrel, a conveying system for material transport and mixing (one or two rotating screws), a die, and heating and cooling systems. Cooling of the material can be done by air, water or by a contact with a cold surface. The extrusion process can result in the formation of strands or films, which can be cut to the required size, an also can be executed using specific downstream equipment setups, which produce dosage forms such as pellets, granules, spheres and tablets $[50,51]$. This technique is simple, efficient, and offers the possibility of continuous manufacture, which makes it one of the most employed industrial solid dispersion manufacturing process. Some examples of polymeric carriers used in hot-melt extrusion are HPMC, HPMCAS, PVP, PVP-vinyl acetate, and Soluplus ${ }^{\circledR}[36,46]$.

\subsubsection{Solvent method}

In the solvent method, the drug and the carrier are solubilized in a common solvent, which is then removed yielding a solid dispersion. Such technique enables dispersion in a molecular level that is preferred to enhance the solubility and stability of the product. Solvent removal may be accomplished by several methods, such as vacuum drying, rotary evaporation, freeze-drying, or spray drying [13, 36, 46]. Commonly used sol- 
vents are methanol, ethanol, ethyl acetate, acetone, methylene chloride, water, among others $[13,46]$.

Spray drying is widely applied in pharmaceutical industry to prepare solid dispersions due to the possibility of continuous manufacturing, ease of scalability, and cost-effectiveness [13, 52]. The spray drying process is used to convert a solution or suspension of a drug and a carrier into a dry powder (amorphous solid dispersion) in a single step $[15,36]$ and involves: (1) the feed solution/suspension is pumped into the drying chamber through a nozzle; (2) the droplets are atomized and come in contact with the drying fluid (hot gas, often air) inside the drying chamber; (3) the dried material is separated from the drying medium using a cyclone and is collected in a collection device; (4) the exhaust gases are filtered via HEPA filters [52,53]. Carriers used in solid dispersions prepared by spray drying are generally the same used in those obtained by fusion methods, including metacrilates, PVP and derivatives, HPMC and HPMCAS [46, 52, 53].

\subsubsection{Fusion-solvent method}

The fusion-solvent method is a combination of the fusion and the solvent methods consisting in heating the carrier to a temperature above its melting point; dissolving the drug in a suitable solvent; incorporating the drug solution in the molten carrier under stirring; removing the solvent, cooling and solidification to form the solid dispersion [13].

\subsubsection{Co-grinding method}

In grinding operation, mechanical energy is applied to physically break down coarse particles into finer ones. When particle size reduction reaches a critical threshold (limit beyond which the material becomes difficult to comminute even prolonging the grinding time), the continued transfer of mechanical energy to the drug leads to partial or complete amorphization [26]. However, drug particles $<30 \mu \mathrm{m}$ produced by grinding have large surface/interfacial area, increased free energy and decreased thermodynamic stability, which can promote particle agglomeration. Also, amorphous material may be thermodynamically unstable, leading to amorphous-crystalline inter-conversions of the drug. Both agglomeration and recrystallization phenomena decrease drug dissolution rate and bioavailability. Co-grinding drugs together with certain excipients, resulting in solid dispersions, can reduce particles agglomeration and drug recrystallization [35, 26].

Examples of carriers employed for preparing solid dispersions by co-grinding in a ball mill are: PVP, crospovidone and microcrystalline cellulose [47]; chitosan [48]; sodium alginate [49]; and poly(vinyl alcohol) (PVA) [54].

\subsection{Technological issues in industrial production}

Solid dispersions may have scaling-up problems when conventional dosage form manufacturing processes are taken into account. The typical soft and tacky characteristics of solid dispersions may result in deficient properties of flow, mixing and compaction, leading to low reproducibility of the physical properties of the final products. Also, the thermal, chemical and mechanical stress applied during processing can induce instability by degradation or recrystallization mechanisms [14]. Although a current need to develop production processes and scale them up to industrial level in a reliable manner still exist, different manufacturing processes are being developed to obtain solid dispersions with adequate robustness and reproducibility [46].

\section{CONCLUSIONS}

The pharmaceutical industry is one of the most profitable industries worldwide and oral solid dosage forms are responsible for most of the drug prescriptions. However, as shown in this work, the development of new pharmaceutical formulations poses certain difficulties, including the achievement of adequate bioavailability for poorly water-soluble drugs. Accordingly, the solid dispersions are an important tool for the pharmaceutical industry, since they are quite effective in improving solubility, dissolution and bioavailability of drugs. Although some aspects still require further improvement, related to the transposition for large-scale production and the physicochemical stability of systems, new carrier materials and manufacturing processes have been studied to overcome such limitations, which may increase the number of products solid dispersionbased on the market. Finally, it is worth noting that although the main focus of this work has been the immediate-release solid dispersions, the technique can also be applied to modify the drug release through proper selection of carrier materials and excipients. This approach has opened room for the expansion of solid dispersion technology in order to obtain sustained-release drug delivery systems. 


\section{ACKNOWLEDGEMENTS}

The authors thank Conselho Nacional de Desenvolvimento Científico e Tecnológico (CNPq) and Coordenação de Aperfeiçoamento de Pessoal de Nível Superior (Capes) for supporting this study.

\section{BIBLIOGRAPHY}

[1] ANSEL, H.C., ALLEN JUNIOR, L.V., POPOVICH, N.G., Formas farmacêuticas e sistemas de liberação de fármacos, 9 ed., Porto Alegre, Artmed, 2013.

[2] ANSELMO, A.C., MITRAGOTRI, S., “An overview of clinical and commercial impact of drug delivery systems”, Journal of Controlled Release, v. 190, n. 28, pp. 15-28, Sep. 2014.

[3] DI, L., FISH, P.V., MANO, T., "Bridging solubility between drug discovery and development", Drug Discovery Today, v. 17, n. 9-10, pp. 486-495, May. 2012.

[4] LIPINSKI, C.A.,"Drug-like properties and the causes of poor solubility and poor permeability", Journal of Pharmacological and Toxicological Methods, v. 44, n. 1, pp. 235-249, Jul.-Aug. 2000.

[5] AMIDON, G. L., LENNERNÃS, H., SHAH, V.P., et al., "A theoretical basis for a biopharmaceutic drug classification: the correlation of in vitro drug product dissolution and in vivo bioavailability", Pharmaceutical Research, v. 12, n. 3, pp. 413-420, Mar. 1995.

[6] KAWABATA, Y., WADA, K., NAKATANI, M.et al., "Formulation design for poorly water-soluble drugs based on biopharmaceutics classification system: Basic approaches and practical applications", International Journal of Pharmaceutics, v.420, n. 1, pp.1-10, Nov. 2011.

[7] SHAH, V.P., AMIDON, G.L., "G.L. Amidon, H. Lennernas, V.P. Shah, and J.R. Crison. A theoretical basis for a biopharmaceutic drug classification: The correlation of in vitro drug product dissolution and in vivo bioavailability, Pharm Res 12, 413-420, 1995-Backstory of BCS", American Association of Pharmaceutical Scientists Journal, v. 16, n. 5, pp. 894-898, Sep. 2014.

[8] VANDANA, K. R., RAJU, Y.P., CHOWDARY, V. H.et al., "An overview on in situ micronization technique - An emerging novel concept in advanced drug delivery", Saudi Pharmaceutical Journal, v. 22, n. 4, pp. 283-289, Sep. 2014.

[9] KURKOV, S.V., LOFTSSON, T., “Cyclodextrins”, International Journal of Pharmaceutics, v. 453, pp. 167-180, Aug. 2013.

[10] KOHLI, K., CHOPRA, S., DHAR, D.et al., "Self-emulsifying drug delivery systems: an approach to enhance oral bioavailability”, Drug Discovery Today, v. 15, n. 21-22, pp. 958-65, Nov. 2010.

[11] NOKHODCHI, A., HENTZSCHEL, C.M., LEOPOLD, C.S., "Drug release from liquisolid systems: speed it up, slow it down”, Expert Opinion on Drug Delivery, v. 8, n. 2,pp.191-205, Feb. 2011.

[12] LU, M., XING, H., JIANG, J. et al., "Liquisolid technique and its applications in pharmaceutics", AsianJournal of Pharmaceutical Sciences, v. 12, n. 2, pp. 115-123, Mar. 2017.

[13] VO, C.L., PARK, C., LEE, B., "Current trends and future perspectives of solid dispersions containing poorly water-soluble drugs", European Journal of Pharmaceutics and Biopharmaceutics, v.85, n.3 (Parte B), pp. 799-813, Nov. 2013.

[14] GURUNATH, S., KUMAR, S. P., BASAVARAJ, N. K. et al., "Amorphous solid dispersion method for improving oral bioavailability of poorly water-soluble drugs", Journal Pharmaceutical Research, v.6, n. 4, pp. 476-480, Apr. 2013.

[15] HE, Y., HO, C., “Amorphous solid dispersions: Utilization and challenges in drugdiscovery and development”, Journal of Pharmaceutical Sciences, v. 104, pp. 3237-3258, Out. 2015.

[16] BAJAJ, H., BISHT, S., YADAV, M.et al., "Bioavailability Enhancement: a Review", International Journal of Pharma and Bio Sciences, v. 2, n. 2, pp. 202-216, Apr.-Jun. 2011.

[17] CARDOSO, S.G., PEZZINI, B.R."Estudo de aspectos técnicos relacionados aos medicamentos e seus impactos na assistência farmacêutica", In: FUTURO, D.O., DIEHL, E.E. et al. (aut), Gestão da Assistência Farmacêutica, 2 ed., Florianópolis, UFSC, 2011).

[18] GUPTA, A.K., SEHRAWAT, S.K.,"Bioavailability enhancement of poorly water soluble drugs: A review”, International Journal of Pharmacy \& Life Sciences, v.2, n. 3, pp. 640-650, Mar. 2011.

[19] HETAL, T., BINDESH, P., SNEHA, T., "A review on techniques for oral bioavailability enhancement of drugs", International Journal of Pharmaceutical Sciences Review and Research, v. 4, n. 3, pp. 203-223, Sep.-Oct. 2010. 
[20] GARCÍA-ARIETA, A.,"Interactions between active pharmaceutical ingredients and excipients affecting bioavailability: Impact on bioequivalence”, European Journal of Pharmaceutical Sciences, v. 65, pp. 89-97, Dez. 2014.

[21] PANAKANTI, R., NARANG, A.S.,"Impact of excipient interactions on drug bioavailability from solid dosage forms", Pharmaceutical Research, v. 29, n. 10, pp. 2639-2659, Oct. 2012.

[22] STORPIRTIS, S., MARCOLONGO, R., GASPAROTTO, F.S. et al., "Equivalência farmacêutica no contexto da intercambialidade entre medicamentos genéricos e de referência: Bases técnicas e científicas", Infarma, v.16, n. 9-10, pp. 51-56, 2004.

[23] ZHANG, G.G.Z., LAW, D., SCHMITT, E.A. et al., "Phase transformation considerations during process development and manufacture of solid oral dosage forms", AdvancedDrug Delivery Review, v. 56, n. 3 , pp. 371-390, Feb. 2004.

[24] PRADO, L.D.; ROCHA, H.V.A., "Estado sólido na indústria farmacêutica: Uma breve revisão", Revista Virtual de Química, v. 7, n. 6, pp. 2080-2112, Ago. 2015.

[25] BRUNTON, L.L., CHABNER, B.A., KNOLLMANN, B.C., Asbases farmacológicas da terapêutica de Goodman e Gilman, 12 ed., Porto Alegre: AMGH, 2012.

[26] LOH, Z.H., SAMANTA, A.K., HENG, P.W.S., "Overview of milling techniques for improving the solubility of poorly water-soluble drugs", Asian Journal of Pharmaceutical Sciences, v. 10, n. 4, pp. 255-274, Jul. 2015 .

[27] GAO, Z., ROHANI, S., GONG, J. et al., "Recent developments in the crystallization process: towardthe pharmaceutical industry", Engineering, v. 3, n. 3, pp. 343-353, Jun. 2017.

[28] SANTOS, O.M.M., REIS, M.E.D., JACON, J.T. et al., "Polymorphism: an evaluation of the potential risk to the quality of drug products from the Farmácia Popular Rede Própria", Brazilian Journal of Pharmaceutical Sciences, v. 50, n. 1, Jan.-Mar. 2014.

[29] KALEPU, S., NEKKANTI, V., "Insoluble drug delivery strategies: review of recent advances and business prospects", Acta Pharmaceutica Sinica B, v. 5, n. 5, p. 442-453, Sep. 2015.

[30] JAMBHEKAR, S.S., BREEN, P.J. "Drug dissolution: significance of physicochemical properties and physiological conditions”, Drug Discovery Today, v. 18, n23-24, pp. 1173-1184, Dec. 2013.

[31] U.S. FDA/CDER Department of health and human Services, Food and drug administration, Center for Drug Evaluation and Research, The Biopharmaceutics Classification System (BCS) Guidance, 2016. Acess in Out., 2017.

[32] SAREEN, S., MATHEW, G., JOSEPH, L. "Improvement in solubility of poor water-soluble drugs by solid dispersion", International Journal of Pharmaceutical Investigation, v. 2, n. 1, pp. 12-17, Jan-Mar. 2012. [33] HUANG, Y., DAI, W., "Fundamental aspects of solid dispersion technology for poorly soluble drugs", Acta Pharmaceutica Sinica B, v. 4, n. 1, pp. 18-25, Feb. 2014.

[34] VASCONCELOS, T., SARMENTO, B., COSTA, P., "Solid dispersions as strategy to improve oral bioavailability of poor water soluble drugs", Drug Discovery Today, v. 12, n. 23-24, pp. 1068-1075, Dec. 2007.

[35] LAITINEN, R., PRIEMEL, P.A., SURWASE, S.et al., "Theoretical considerations in developing amorphous solid dispersions", In: SHAH, N., SANDHU, H., CHOI, D.S., et al., (eds), Amorphous solid dispersions: Theory and practice, New York, USA, Springer, 2014.

[36] BAGHEL, S., CATHCART, H., O'REILLY, N.J., "Polymeric amorphous solid dispersions: A review of amorphization, crystallization, stabilization, solid-state characterization, and aqueous solubilizationof biopharmaceutical classification system class II drugs", Journal of Pharmaceutical Sciences, v.105, n. 9, pp. 2527-2544, Sep. 2016.

[37] NEWMAN, A., Pharmaceutical amorphous solid dispersions, 1 ed., New York: Wiley, 2015.

[38] HE, Y., HO, C., "Amorphous solid dispersions: utilization and challenges in drug discovery and development", Journal of Pharmaceutical Sciences, v. 104, n. 10, pp. 3237-3258, Out. 2015.

[39] SEKIGUCHI, K., OBI, N., "Studies on absorption of eutectic mixture. I. A comparison of the behavior of eutectic mixture of sulfathiazole and that of ordinary sulfathiazole in man", Chemical and Pharmaceutical Bulletin, v. 9, pp. 866-872, 1961.

[40] DUONGA, T.V., MOOTER, G.V.D., "The role of the carrier in the formulation of pharmaceutical solid dispersions. Part I: crystalline and semi-crystalline carriers", Expert Opinion on Drug Delivery, v. 13, n. 11, pp. 1583-1594, Nov. 2016.

[41] DUONGA, T.V., MOOTER, G.V.D., "The role of the carrier in the formulation of pharmaceutical solid 
dispersions. Part II: amorphous carriers”, Expert Opinion on Drug Delivery, v. 13, n. 12, pp. 1681-1694, Jun. 2016.

[42] CHAUDHARI, S.P., DUGAR, R.P., “Application of surfactants in solid dispersion technology for improving solubility of poorly water soluble drugs", Journal of Drug Delivery Science and Technology, v. 41, pp.68-77, Oct. 2017.

[43] THAO, T.D.T., PHUONG, H.L.T.,"Perspectives on strategies using swellable polymers in solid dispersions for controlled drug release”, Current Pharmaceutical Design, v. 23, n. 11, pp. 1639-1648, Mar. 2017.

[44] TEJA, S.B., PATIL, S.P., SHETE, G., et al., "Drug-excipient behavior in polymeric amorphous solid dispersions", Journal of Excipients and Food Chemicals, v. 4, n. 3, Sep. 2013.

[45] QIAN, F., HUANG, J., HUSSAIN, M.A., “Drug-polymer solubility and miscibility: stability consideration and practical challenges in amorphous solid dispersion", Journal of Pharmaceutical Sciences, v. 99, n. 7, pp. 2941-2947, Jul. 2010.

[46] VASCONCELOS, T., MARQUES, S., NEVES, J., et al.,“Amorphous solid dispersions: Rational selection of a manufacturing process”, Advanced Drug Delivery Reviews, v. 100, pp. 85-101, May 2016.

[47] BARZEGAR-JALALI, M., VALIZADEH, H., SHADBAD, M.-R.S., et al., "Cogrinding as an approach to enhance dissolution rate of a poorly water-soluble drug (gliclazide)", Powder Technology, v. 197, n. 3, pp. 150-158, Jan. 2010.

[48] ZHONG, L., ZHU, X., LUO, X., et al.,"Dissolution properties and physical characterization of telmisartan-chitosan solid dispersions prepared by mechanochemicalactivation", AAPS PharmSciTech, v. 14, n.2, pp. 541-50, Jun. 2013.

[49] BORBA, P.A.A., PINOTTI, M., CAMPOS, C.E.M., et al., "Sodium alginate as a potential carrier in solid dispersion formulations to enhance dissolution rate and apparent water solubility of BCS II drugs", Carbohydrate Polymers, v. 137, pp. 350-359, Feb. 2016.

[50] CROWLEY, M.M., ZHANG, F., REPKA, M.A.et al., "Pharmaceutical applications of hot-melt extrusion: part I", Drug Development and Industrial Pharmacy, v. 33, n. 9, pp. 909-926, Sep. 2007.

[51] STANKOVIĆ, M., FRIJLINK, H.W., HINRICHS, W.L.J., "Polymeric formulations for drug release prepared by hot melt extrusion: application and characterization", Drug Discovery Today, v. 20, n. 7, pp. 812-823, Jul. 2015.

[52] PATEL, B.B., PATEL, J.K., CHAKRABORTY, S., et al., "Revealing facts behind spray dried solid dispersion technology used for solubility enhancement”, Saudi Pharmaceutical Journal, v. 23, n. 4, pp. 352365, Sep. 2015.

[53] SINGH, A., VAN DEN MOOTER, G., "Spray drying formulation of amorphous solid dispersions", $A d$ vanced Drug Delivery Reviews, v. 100, pp. 27-50, May. 2016.

[54] ISAAC, J., GANGULY, S. GHOSH, A., "Co-milling of telmisartan with poly(vinyl alcohol) - An alkalinizer free green approach to ensure its bioavailability", European Journal of Pharmaceutics and Biopharmaceutics, v. 101, pp. 43-52, Apr. 2016. 